\title{
RNA Synthesis Inhibition
}

National Cancer Institute

\section{Source}

National Cancer Institute. RNA Synthesis Inhibition. NCI Thesaurus. Code C40667.

RNA Synthesis Inhibition involves interference with, or restraint of, the activities involved

in the polymeric linkage of ribose purine and pyrimidine nucleotides together by

phosphate groups attached to their 5-prime and 3-prime sugar hydroxyls. 